\title{
Intrinsic Mechanisms of Antinociception in Inflammation: Local Opioid Receptors and $\beta$-Endorphin
}

\author{
C. Stein, ${ }^{2}$ C. Gramsch, ${ }^{1, a}$ and A. Herz ${ }^{1}$ \\ 'Department of Neuropharmacology, Max-Planck-Institut für Psychiatrie, D-8033 Martinsried, and ${ }^{2}$ Department of \\ Anesthesiology, Ludwig-Maximilians-Universität, Klinikum Grosshadern, D-8000 München 70, Federal Republic of Germany
}

This study examined antinociception induced through the activation of local opioid receptors in inflammation by endogenous opioids. Rats developed a unilateral localized inflammation upon injection of Freund's adjuvant into one hindpaw. Four to $6 \mathrm{~d}$ later they were subjected to cold water swim (CWS), an environmental stimulus known to activate intrinsic opioid systems. Following CWS (1 min) the animals' withdrawal threshold to noxious pressure applied onto the paws increased significantly more on the inflamed paw than on the noninflamed paw. This unilateral antinociceptive effect in inflamed paws was dose-dependently and stereospecifically reversible by intraplantar (i.pl.) but not systemic (i.v. or s.c.) administration of the opioid antagonist naloxone (18 $\mu \mathrm{g})$. This suggested that CWS-induced antinociception in inflamed tissue was brought about by the activation of local opioid receptors. Antiinflammatory or vasoconstrictive events, as measured by paw volume and temperature, did not contribute to this unilateral antinociception. Receptorselective antagonists indicated the involvement of $\mu$ - and $\delta$ but not $\boldsymbol{\kappa}$-receptors. Intravenous application of a universal antibody to endogenous opioid peptides (3-E7) and a specific antibody to $\beta$-endorphin, but not antisera against metenkephalin or dynorphin, abolished the CWS effect. Finally, the i.pl. injection of synthetic $\beta$-endorphin (1-31) produced an antinociceptive effect in inflamed paws which was reversible by i.pl. naloxone and selective $\mu$ - and $\delta$-receptor antagonists. These findings suggest that antinociception in inflamed tissue can be induced through the activation of local opioid receptors by endogenous $\beta$-endorphin released during CWS.

Traditionally, antinociception produced by exogenous as well as endogenous opioids has been associated with activation of opioid receptors in the central nervous system. Recently, however, we and others have demonstrated that exogenous opioid agonists can exert antinociceptive effects by interacting with local opioid receptors in inflamed tissue of the rat (Ferreira and Nakamura, 1979; Joris et al., 1987; Stein et al., 1988b, 1989a).

\footnotetext{
Reccived Junc 20, 1989; revised Oct. 11, 1989; accepted Nov. 8, 1989.

This work was supported by Deutsche Forschungsgemeinschaft, Bonn. We thank G. Kahleis for secretarial assistance, S. Kosin for technical assistance, and U. Bäuerle for preparation of the figures. We appreciate the stimulating discussions with Drs. T. Costa and T. S. Shippenberg throughout the study.

Correspondence should be addressed to Dr. C. Stein, Department of Anesthesiology, Klinikum Grosshadern, D-8000 München 70, FRG.

a Present address: Department of Pharmacology, Toxicology and Pharmacy, Faculty of Veterinary Medicine, Ludwig-Maximilians-Universität, Königinstr. 16 , D-8000 München 22, FRG.

Copyright (C) 1990 Society for Neuroscience $0270-6474 / 90 / 041292-07 \$ 02.00 / 0$
}

Furthermore, we have been able to differentiate the types of opioid receptors involved (Stein et al., 1989a). The physiological significance of these receptors, however, is yet to be elucidated. In particular, the question arises as to which are the endogenous ligands for these receptors and what stimuli call them into play.

Three families of endogenous opioid peptides derived from 3 precursor peptides are known to date: the pro-opiomelanocortin (POMC), the pro-enkephalin, and the pro-dynorphin system. These precursors undergo differential processing in the various regions of the central and peripheral nervous systems (Höllt, 1986; Lewis et al., 1987) and the major cleavage products have differing affinities to the 3 opioid receptor types $\mu, \delta$, and $\kappa$. Intrinsic opioid antinociceptive systems can be activated by certain environmental stimuli (Terman et al., 1984; Millan and Herz, 1985; Bodnar, 1986). Out of a wide variety of models we chose cold water swim (CWS) and examined its ability to elicit antinociception through local opioid receptor-specific mechanisms in inflammation.

Specifically, this study investigated (1) the antinociceptive effect of different durations of CWS in unilateral hindpaw inflammation, (2) whether this effect is reversible by locally, compared to systemically, applied naloxone and its stereoisomer, (3) whether antiinflammatory and/or vasoconstrictive events contribute to this antinociception, (4) which types of opioid receptors are involved, (5) whether this effect can be abolished by antibodies against endogenous opioid peptides, and (6) whether this effect can be mimicked by local administration of the opioid peptide $\beta$-endorphin.

Stereospecific and dose-dependent reversibility by local, but not systemic, application of naloxone provides evidence for an involvement of peripherally located opioid receptors. Differential abolition of an effect by antagonists that are highly selective for particular receptor types and by specific antibodies will point to the identity of the endogenous ligand(s) involved. Imitation of this effect by exogenous administration of the putative ligand will confirm its functional significance. Using these criteria we have concluded that antinociception in inflamed tissue can be induced through activation of local $\mu$ - and $\delta$-opioid receptors by endogenous $\beta$-endorphin released during CWS.

\section{Materials and Methods}

Subjects. Experiments were carried out in male Wistar rats (Ivanovas, Kisslegg, FRG) (180-200 gm) housed individually in cages lined with sawdust. Standard laboratory rodent chow and water were available ad libitum. Room temperature and relative humidity were maintained at $22 \pm 0.5^{\circ} \mathrm{C}$ and $60 \%$, respectively. A $12 \mathrm{hr} / 12 \mathrm{hr}$ (8 A.M. $/ 8$ P.M.) lightdark cycle was used. All testing was conducted in the light phase. The guidelines on ethical standards for investigations of experimental pain in animals (Zimmermann, 1983) were followed. 
Induction of inflammation. The inflammatory agent used was modified Freund's complete adjuvant (FCA), containing $0.1 \%$ heat-killed and dried Mycobacterium butyricum in $85 \%$ Marcol 52 and $15 \%$ Aracel A mannide monooleate emulsifier (Calbiochem, La Jolla, CA). Rats received an intraplantar injection of $0.15 \mathrm{ml}$ of this suspension into the right hindfoot under brief ether anesthesia. Control animals were anesthetized but not injected. Inflammation of the injected paws was apparent within $12 \mathrm{hr}$ following treatment with FCA. A detailed description of the time course and magnitude of the inflammatory reaction is given elsewhere (Stein et al., 1988a). In all rats studied, the inflammation remained confined to the inoculated paw. All testing was conducted between 4 and $6 \mathrm{~d}$ postinoculation.

Parameters of inflammation. Paw volume was measured by submerging the hindpaw to the tibiotarsal joint into the water-filled Perspex cell of a plethysmometer (Ugo Basile, Comerio, Italy). The volume of displacement, which is equal to the paw volume, was indicated on a digital display. The surface temperature of the plantar skin was measured with an Infrared radiation thermometer (Ultrakust, Ruhmannsfelden, FRG).

Algesiometric testing. Antinociceptive effects were evaluated using the paw pressure test. The animal was gently restrained under paper wadding and incremental pressure applied via a wedge-shaped, blunt piston onto an area of $1.75 \mathrm{~mm}^{2}$ of the dorsal surface of the hindpaw by means of an automated gauge (Ugo Basile, Comerio, Italy). The pressure required to elicit paw withdrawal, the paw pressure threshold (PPT), was determined. A cutoff of $250 \mathrm{gm}$ was employed. Three consecutive trials, separated by intervals of $10 \mathrm{sec}$, were conducted and the average determined. The same procedure was then carried out on the contralateral side; the sequence of sides was alternated between subjects to preclude "order" effects. Separate groups of animals were used for each treatment, with the observer blind to the experimental condition employed.

Drugs and their administration. The following drugs were used: naloxone-HCl (DuPont, Geneva, Switzerland), (+)-naloxone-HCl (National Institute on Drug Abuse), (D-Phe)-Cys-Tyr-(D-Trp)-Orn-Thr-Pen-Thr$\mathrm{NH}_{2}$ (CTOP) (Peninsula Laboratories Inc., Belmont, CA), $N, N$-diallylTyr-Aib-Aib-Phe-Leu (ICI 174,864) (Cambridge Research Biochemicals, Ltd., Cambridge, UK), nor-binaltorphimine (nor-BNI) (courtesy of Dr. A. W. Lipkowski, University of Minnesota), $\beta$-endorphin (1-31) ( $\beta$-EP) (Novabiochem AG, Läufelfingen, Switzerland), halothane and ether (Hoechst AG, Frankfurt a.M., FRG). Doses were calculated as the free base and drugs were dissolved in the following vehicles: sterile saline [nor-BNI, naloxone- $\mathrm{HCl},(+)$-naloxone- $\mathrm{HCl}$ ] and sterile water (CTOP, ICI $174,864, \beta$-EP). Routes and volumes of drug administration were: intraplantar (i.pl.) $(100 \mu \mathrm{l})$, subcutaneous (s.c.) $(200 \mu \mathrm{l})$ into a skinfold in the neck, and intravenous (i.v.) $(200 \mu \mathrm{l})$ via a 24-gauge indwelling plastic cannula (Insyte, Becton Dickinson, Sandy, UT) into a tail vein. Antagonists were given concomitantly with agonists in a total volume of $200 \mu \mathrm{l}$. All substances were injected under brief halothane anesthesia

Antisera. A monoclonal antibody (3-E7) against virtually all opioid peptides (Gramsch et al., 1983) as well as polyclonal antibodies from rabbit against $\beta$-EP, methionine-enkephalin (ME), and dynorphin A (117) (DYN) were generated in our laboratory. All antibodies were purified by chromatography on staphylococcal protein A-Sepharose (Pharmacia, Freiburg, FRG) and tested for binding activity and specificity in standard radioimmunoassays. Cross-reactivities are shown in Table 1 . The $\lg G$ fraction of antisera was dissolved in saline and doses were calculated in $\mu \mathrm{g} \mathrm{IgG}$. Control experiments for nonspecific binding were carried out with purified normal rabbit IgG.

Experiment 1. Antinociceptive effects of different durations of CWS in controls and in animals with unilateral hindpaw inflammation were examined.

Baseline PPTs were taken and rats were returned to their home cages. Ten minutes later, rats were placed into a tub $(20 \mathrm{~cm}$ deep $)$ containing water at $1-2^{\circ} \mathrm{C}$. Separate groups $(n=6)$ of animals were exposed to CWS for $0.5,1$, and 2 min, respectively. PPTs were redetermined at 1 , 5 , and $15 \mathrm{~min}$ following CWS.

The data were analyzed as follows. The increase in PPT was expressed as percentage of maximum possible effect (\% MPE) according to the following formula: \% MPE = (post CWS PPT - basal PPT): $(250$ basal PPT $\times 100$. At the time of peak effect $(1 \mathrm{~min}$ post CWS), elevations of PPT in right paws were compared to those in left paws using Wilcoxon's matched-pairs test. PPT elevations in control animals were compared to those in FCA-treated animals using the Mann Whitney $U$-Test (Kirk, 1982).

Experiment 2. This experiment examined whether the antinociceptive effect following CWS in inflamed paws was brought about by a local opioid receptor-specific mechanism. To test this hypothesis, various doses of i.pl. (-)-naloxone were administered prior to CWS. Equivalent doses were also given s.c. and i.v. to exclude a central site of action. Stereospecificity of antagonism was assessed using the inactive dextrorotatory isomer of naloxone. A CWS duration of $1 \mathrm{~min}$ was chosen since it produced a consistent elevation of PPT in inflamed paws while not significantly affecting PPT in noninflamed paws.

Following baseline PPT recordings, 5 groups $(n=6)$ of rats were given the following injections under brief halothane anesthesia: 3 groups received either saline $(0.1 \mathrm{ml}),(-)$-, or $(+)$-naloxone $(18 \mu \mathrm{g})$ into the right hindpaw; the fourth and fifth groups received (-)-naloxone (18 $\mu \mathrm{g}) \mathrm{i}$.v. and s.c., respectively. Ten minutes later, the animals were subjected to CWS for $1 \mathrm{~min}$ and PPT were reevaluated at 1,5 , and $15 \mathrm{~min}$ post CWS.

A separate experiment examined the dose-response relationship of i.pl. naloxone. After determination of baseline PPT, 4 groups of animals received saline and 6,12 , or $18 \mu \mathrm{g}$ of (-)-naloxone i.pl. $10 \mathrm{~min}$ before CWS. PPT were recorded 1 min thereafter.

In previous control experiments we have shown that i.pl. injections of saline, (+)-, and (-)-naloxone alone are without effect in both FCAtreated and normal rats (Stein et al., 1989a).

The data were analyzed as follows: elevation of PPT (in \% MPE) in the inflamed paw was compared to that in the contralateral paw using Wilcoxon's test, the (1-tailed) hypothesis being that the former is greater than the latter (Kirk, 1982). This analysis was performed for each measurement $(1,5$, and 15 min post CWS) and the Bonferroni correction was applied as appropriate. In the group given (-)-naloxone (18 $\mu \mathrm{g}$ i.pl.), average PPT obtained at the 4 time points were analyzed separately for each side by Friedman's analysis of variance. The null hypothesis was that there is no change in PPT over time.

To construct a dose-response curve, PPT elevation (in \% MPE) was plotted against the dose of $(-)$-naloxone. $A$ linear regression analysis of variance (ANOVA) was performed to test the zero slope hypothesis (Kirk, 1982).

Experiment 3. This experiment examined the effect of 1 min CWS upon hindpaw volume and temperature. Two groups of rats $(n=6)$ received either saline $(0.1 \mathrm{ml})$ or $(-)$-naloxone $(18 \mu \mathrm{g})$ into the inflamed paw; baseline values were then taken and $10 \mathrm{~min}$ later the animals were subjected to $1 \mathrm{~min}$ CWS. Both parameters were redetermined immediately thereafter.

Changes in paw volume and temperature were expressed as percentage of baseline values $(100 \%)$. Left and right paws were then compared using the Wilcoxon test and between-group comparisons were made using the Mann-Whitney test.

Experiment 4. In this experiment we sought to clarify which types of opioid receptors are involved in the mediation of the antinociceptive effect of CWS in inflammation. To examine this question, $\mu-, \delta-$, and k-selective antagonists (Cotton et al., 1984; Gulya et al., 1986; Portoghese et al., 1987) were administered prior to CWS into inflamed paws. The protocol was analogous to the foregoing: 3 groups $(n=5-6)$ received i.pl. CTOP $(0.25,0.5$, and $1 \mu \mathrm{g})$, another 3 groups were given ICI $174,864(5,10$, and $20 \mu \mathrm{g})$, and 4 groups received nor-BNI $(50$,

Table 1. Relative cross-reactivities of antibodies with opioid peptides in radioimmunoassay

\begin{tabular}{lrlcc} 
& \multicolumn{5}{l}{ Cross-reactivities (\%) } \\
\cline { 2 - 5 } Peptides & 3 -E7 & $\beta$-EP & ME & DYN \\
\hline$\beta$-endorphin (1-31) & 100 & 100 & 0.5 & $<0.001$ \\
$\alpha$-endorphin & 100 & $<0.001$ & 0 & 0 \\
$\gamma$-endorphin & 100 & 0.1 & 0 & 0 \\
Met-enkephalin & 80 & 0.05 & 100 & $<0.005$ \\
Leu-enkephalin & 80 & 0 & 10 & $<0.005$ \\
DYN A (1-17) & 0 & 0 & $<0.05$ & 100 \\
DYN A (1-13) & 16 & 0 & 0 & 0 \\
DYN A (1-8) & 0 & 0 & 0 & $<0.005$ \\
\hline
\end{tabular}

$\mathrm{IC}_{50}$ is taken as $100 \%$.

$0=$ not tested.

Data on 3-E7 from Gramsch et al., 1983. 


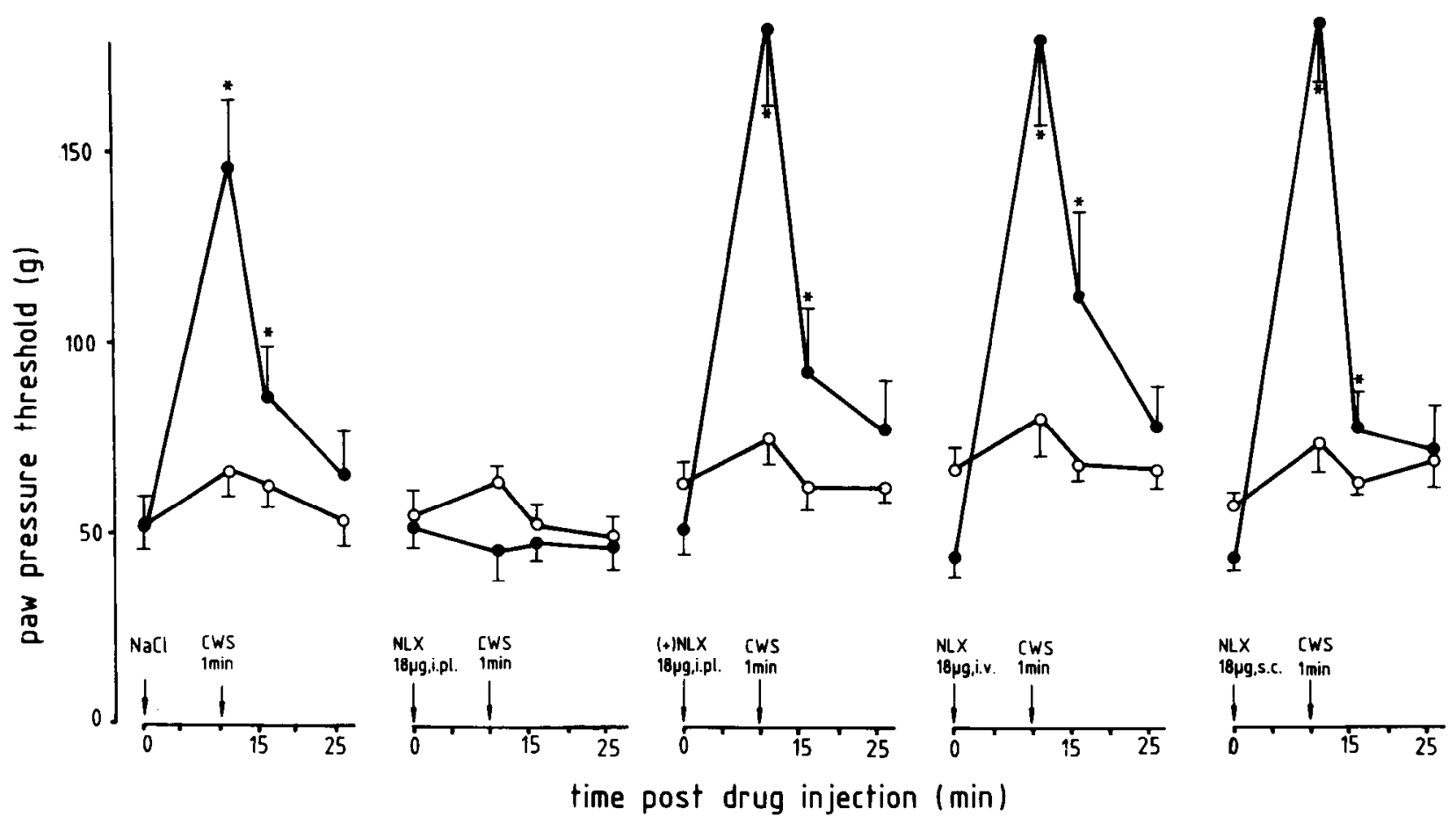

Figure 1. Effect of i.pl. saline, (-)-naloxone (NLX), and (+)-naloxone and of i.v. and s.c. (-)-naloxone on CWS (1 min) induced PPT elevation. Injections were made $10 \mathrm{~min}$ before CWS. Closed symbols, inflamed paw; open symbols, noninflamed paw. Values are means \pm SE $(n=5-6)$. *Significance of differences between PPT elevations in right and left paws: $p<0.05$ (Wilcoxon test).

$100,200$, and $400 \mu \mathrm{g}) 5 \mathrm{~min}$ before CWS. PPT were recorded $1 \mathrm{~min}$ post CWS. All doses and times of administration were chosen based on pilot experiments (see also Stein et al., 1989a). The effects of i.pl. CTOP $(1 \mu \mathrm{g})$, ICI $174,864(20 \mu \mathrm{g})$, and nor-BNI $(400 \mu \mathrm{g})$ without CWS were determined in 3 separate groups of rats.

Increases in PPT (in \% MPE) were plotted against the dose and a linear regression ANOVA was used to test the zero slope hypothesis. Data obtained in control experiments without CWS were analyzed by the Friedman test, the hypothesis being that there is no change in PPT.

Experiment 5. This experiment examined whether the antinociception induced by CWS in inflamed paws could be abolished by antibodies against endogenous opioid peptides. Analogous to the above protocols, separate groups of rats $(n=5-6)$ received i.v. injections of a pan-opioid antibody (3-E7) $(0.05,0.15,0.25,0.5$, and $1.0 \mu \mathrm{g})$ as well as specific antibodies to $\beta$-EP $(0.25,0.5$, and $1.0 \mu \mathrm{g})$ to $\mathrm{ME}(1,4$, and $8 \mu \mathrm{g})$ and to DYN $(1,4$, and $8 \mu \mathrm{g}) 5 \mathrm{~min}$ before CWS. In control experiments for nonspecific binding, normal rabbit IgG $(5 \mu \mathrm{g})$ was administered. PPT were measured $1 \mathrm{~min}$ post CWS. All doses and time intervals for testing were chosen based on pilot experiments. The effects of the respective maximum doses of antisera without CWS were determined in separate groups of FCA-treated rats.

Elevations of PPT (in \% MPE) were plotted against dose and the data were subjected to linear regression ANOVA. Data obtained in control experiments were analyzed by the Friedman test.

Experiment 6 . This experiment examined whether the antinociceptive effect of CWS could be mimicked by i.pl. administration of $\beta$-EP. After determination of baseline PPT, 3 groups of rats $(n=5-6)$ received $\beta$-EP into both hindpaws $(0.25,0.5$, and $1 \mu \mathrm{g}$ per paw) under brief halothane anesthesia. PPT were reevaluated at 5,10 , and 20 min postinjection. Doses and testing intervals were chosen based on pilot experiments.

Analogously to the previous experiments, PPT elevation (in \% MPE) in the right paw was compared to that in the left paw using Wilcoxon's test. Dose-response curves were constructed by plotting the increase of PPT (\% MPE) at the time of peak effect $(5 \mathrm{~min})$ against the dose and were then subjected to a linear regression ANOVA.

Table 2. Effect of CWS on the paw pressure threshold (PPT) in control animals and in rats with inflammation of the right hindpaw (treated)

\begin{tabular}{|c|c|c|c|c|c|c|}
\hline & \multicolumn{6}{|c|}{ CWS duration (min) } \\
\hline & \multicolumn{2}{|l|}{0.5} & \multicolumn{2}{|l|}{1} & \multicolumn{2}{|l|}{2} \\
\hline & $\overline{\text { Pre }}$ & Post & Pre & Post & Pre & Post \\
\hline \multicolumn{7}{|l|}{ Controls } \\
\hline Right & $73 \pm 6$ & $93 \pm 7$ & $58 \pm 3$ & $100 \pm 11$ & $71 \pm 4$ & $147 \pm 16$ \\
\hline Left & $60 \pm 4$ & $85 \pm 5$ & $57 \pm 4$ & $94 \pm 16$ & $60 \pm 3$ & $181 \pm 15$ \\
\hline \multicolumn{7}{|l|}{ Treated } \\
\hline Inflamed & $58 \pm 6$ & $71 \pm 7$ & $52 \pm 10$ & $* 160 \pm 18$ & $46 \pm 4$ & $* 250 \pm 0$ \\
\hline Noninflamed & $74 \pm 8$ & $70 \pm 12$ & $70 \pm 6$ & $72 \pm 8$ & $69 \pm 4$ & $132 \pm 23$ \\
\hline
\end{tabular}

PPT (in gm) at time of maximum effect ( 1 min post CWS). Means \pm SE ( $n=6$ per group).

Pre = baseline; Post $=$ after CWS.

* Significance of differences between PTT elevations in inflamed and noninflamed paws: $p<0.05$ (Wilcoxon test). 


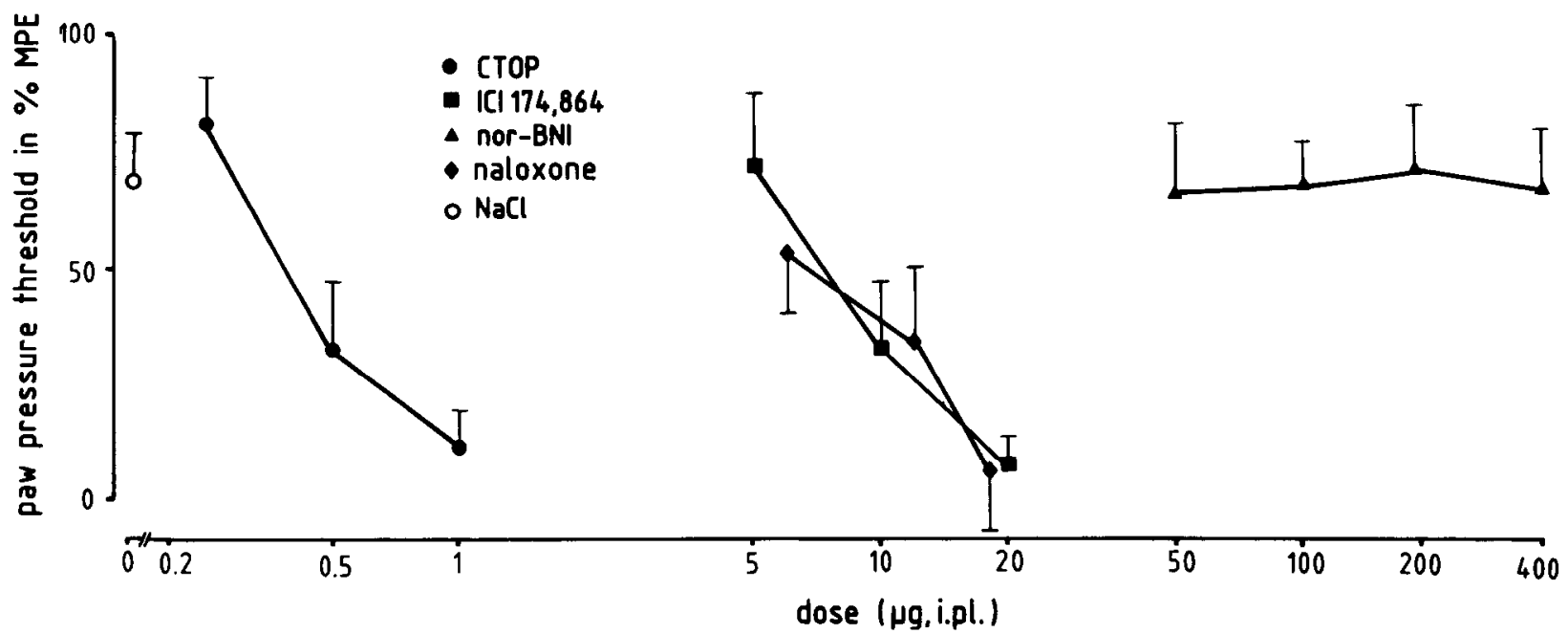

Figure 2. Dose-response relationships of effects of i.pl. (-)-naloxone and selective antagonists for $\mu$ - (CTOP), $\delta$ - (ICI 174,864) and $k$ - (nor-BNI) receptors upon PPT elevation induced by $1 \mathrm{~min}$ CWS in inflamed paws. Values are means $\pm \mathrm{SE}(n=5-6$; ANOVA see text).

Whether the antinociceptive effect of i.pl. $\beta$-EP could be reversed by the same antagonists as used in the foregoing experiments was finally examined. To assess this question, the same doses of (-)-naloxone, CTOP, ICI 174,864, nor-BNI, and $\mathrm{NaCl}$ were injected concomitantly with $\beta$-EP $(1 \mu \mathrm{g})$ in to inflamed paws. PPT were measured $5 \mathrm{~min}$ postinjection. Fourteen separate groups $(n=5-6)$ of rats were used. Data analysis was analogous to experiment 4 .

\section{Results}

Experiment 1. CWS produced an elevation of PPT that reached its maximum at $1 \mathrm{~min}$ post CWS and returned to baseline values within 10-15 min post CWS (see Fig. 1). The magnitude of this elevation increased with increasing CWS duration. In control animals, the increases in PPT produced by CWS were not different between left and right hindpaws (Wilcoxon), nor were they different from those of noninflamed (left) paws of treated animals (Mann-Whitney; Table 2). In FCA-treated animals, the elevation of PPT was significantly greater in inflamed paws than in contralateral, noninflamed paws ( $p<0.05$, Wilcoxon) or in controls $(p<0.05$, Mann-Whitney) at all CWS durations except $0.5 \mathrm{~min}$ (Table 2).

Experiment 2 . One minute CWS resulted in a significantly ( $p$ $<0.05$, 1-tailed Wilcoxon test) higher elevation of PPT in inflamed compared with noninflamed paws in the 4 groups receiving either i.pl. saline, i.pl. (+)-naloxone, or systemic (i.v. or s.c.) (-)-naloxone (Fig. 1). This effect was antagonized dose- dependently by i.pl. (-)-naloxone (Fig. 2), being completely abolished at a dose of $18 \mu \mathrm{g}$ (Fig. 1) (Friedman test). Trend analysis revealed: PPT by dose of $(-)$-naloxone, $F(3,20)=3.4$, $p<0.05$, linear regression, $F(1,20)=10.1, p<0.005$.

Experiment 3. Paw volume did not change significantly during CWS in either saline- or (-)-naloxone-pretreated animals (Table 3). Paw temperature dropped to the same extent (ca. 50\%) in both inflamed and noninflamed paws (Wilcoxon). This decrease was not significantly different between saline- and (-)naloxone-pretreated groups (Mann-Whitney, Table 3).

Experiment 4. The increase of PPT in inflamed paws produced by CWS was dose-dependently reversed by specific $\mu$ (CTOP) and $\delta$ - (ICI 174,864) but not $\kappa$ - (nor-BNI) antagonists (Fig. 2). Trend analysis was as follows. PPT by dose of CTOP: $F(2,15)=8.5, p<0.005$, linear regression, $F(1,15)=16.3, p$ $<0.005$; ICI 174,864: $F(2,14)=5.7, p<0.05$, linear regression, $F(1,14)=11.1, p<0.01$; nor-BNI: $F(3,18)=0.03, p>0.05$. Neither antagonist given alone produced significant changes in PPT (Friedman test, Table 4).

Experiment 5. The elevation of PPT induced by CWS (1 min) was dose-dependently antagonized by 3-E7 and the antibody against $\beta$-EP but not by antibodies to ME or DYN or by IgG (Fig. 3). Trend analysis was: PPT by dose of 3-E7: $F(4,22)=$ $4.8, p<0.01$, linear regression, $F(1,22)=18.9, p<0.001$; $\beta$-EP antibody: $F(2,13)=24.3, p<0.001$, linear regression,

Table 3. Effects of $1 \mathrm{~min}$ CWS on volume and temperature of hindpaws in saline and ( - )-naloxone (NLX) pretreated animals

\begin{tabular}{|c|c|c|c|c|}
\hline & \multicolumn{2}{|c|}{ i.pl. $\mathrm{NaCl}(100 \mu \mathrm{l})$} & \multicolumn{2}{|c|}{ i.pl. NLX $(18 \mu \mathrm{g})$} \\
\hline & Pre & Post & Prc & Post \\
\hline \multicolumn{5}{|l|}{ Volume (ml) } \\
\hline Inflamed & $3.42 \pm 0.06$ & $3.41 \pm 0.15$ & $3.28 \pm 0.05$ & $3.42 \pm 0.1$ \\
\hline Noninflamed & $1.47 \pm 0.04$ & $1.44 \pm 0.03$ & $1.51 \pm 0.02$ & $1.47 \pm 0.03$ \\
\hline \multicolumn{5}{|l|}{ Temperature $\left({ }^{\circ} \mathrm{C}\right)$} \\
\hline Inflamed & $33.5 \pm 0.7$ & $16.8 \pm 0.3$ & $31.9 \pm 0.9$ & $14.6 \pm 0.5$ \\
\hline Noninflamed & $31.1 \pm 0.8$ & $17.5 \pm 0.5$ & $29.6 \pm 0.7$ & $14.4 \pm 0.6$ \\
\hline
\end{tabular}

Means $\pm \operatorname{SE}(n=6$ per group) 


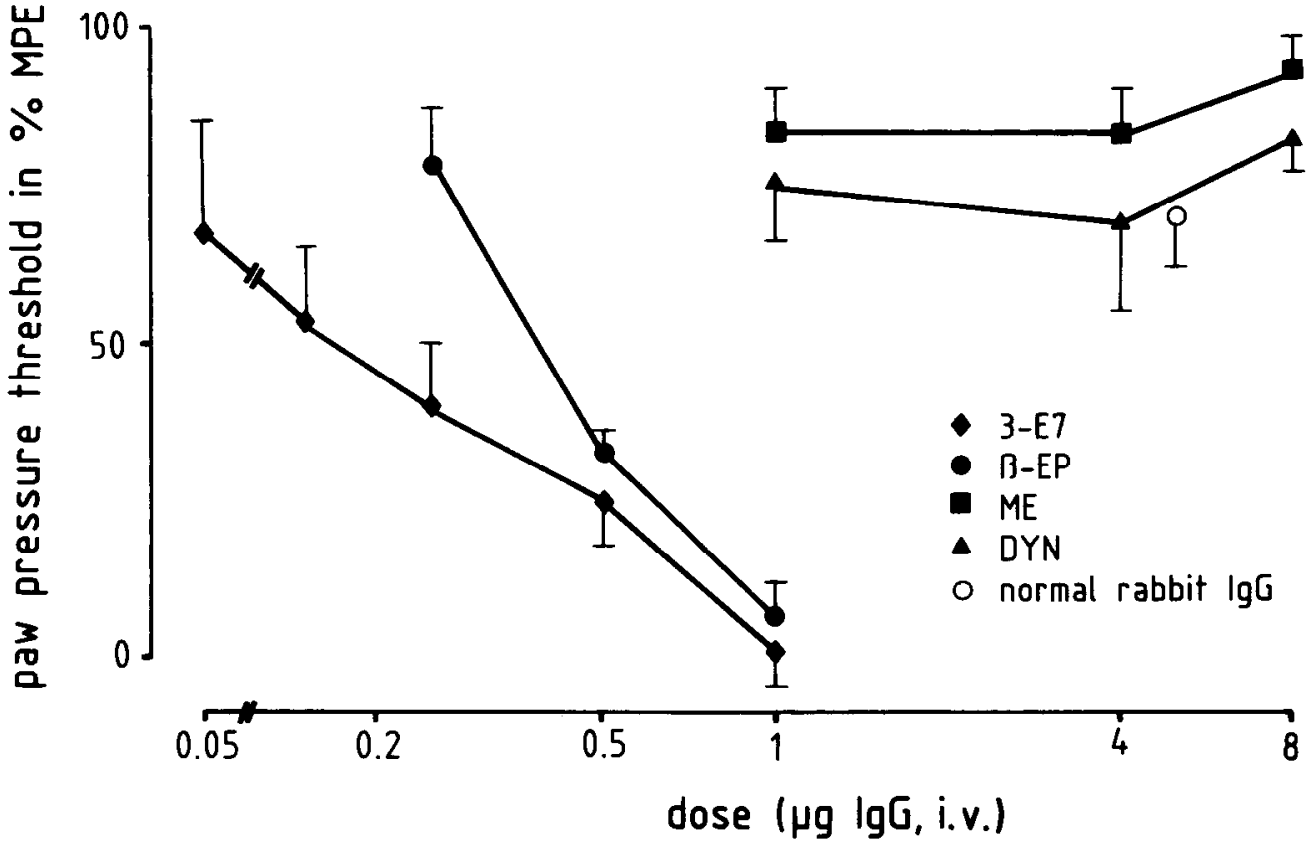

Figure 3. Effects of purified antibodies against all opioid peptides (3-E7), $\beta$-endorphin ( $\beta$-EP), met-enkephalin (ME), and dynorphin A (1-17) (DYN) upon PPT elevation induced by $1 \mathrm{~min}$ CWS in inflamed paws. The IgG fraction of antisera was applied i.v. and doses are given as $\mu \mathrm{g}$ IgG. Values are means \pm SE $(n=5-6$; ANOVA see text).
$F(1,13)=48.6, p<0.001 ; \mathrm{ME}$ antibody: $F(2,15)=0.7, p>$ 0.05 ; DYN antibody: $F(2,14)=0.3, p>0.05$. Neither antiserum given alone produce significant alterations in PPT (Friedman test, Table 4).

Experiment 6. Intraplantar administration of $\beta$-EP $(0.25-1$ $\mu \mathrm{g})$ produced dose-dependent PPT elevations in inflamed but not in contralateral noninflamed paws (Fig. 4). Trend analysis of data on inflamed paws revealed: PPT by dose, $F(2,17)=5.2$, $p<0.05$, linear regression, $F(1,17)=9.4, p<0.01$.

The increase in PPT produced by $\beta$-EP $(1 \mu \mathrm{g}$ i.pl. $)$ in inflamed

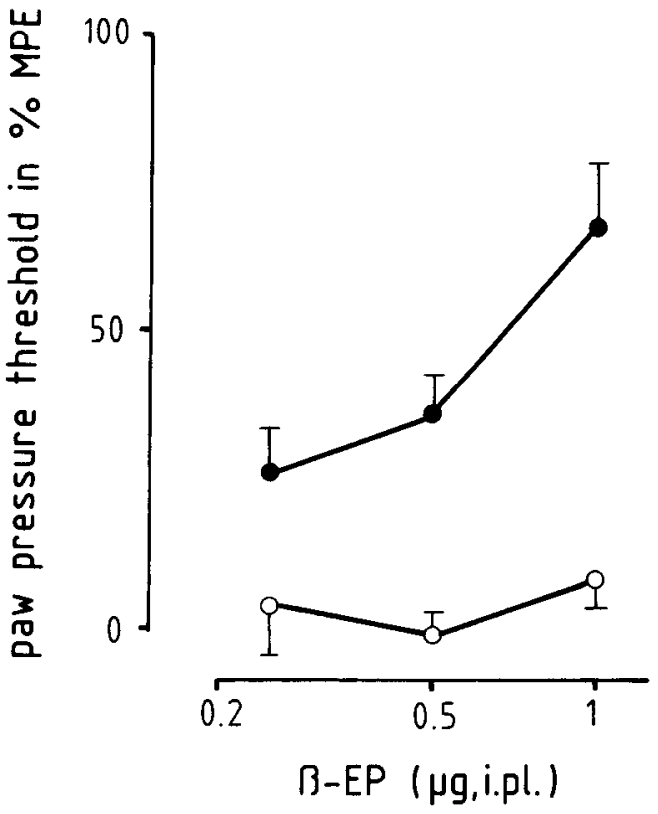

Figure 4. Effect of i.pl. $\beta$-EP upon PPT in noninflamed (open symbols) and inflamed paws (closed symbols). Measurements were conducted at time of peak effect $(5 \mathrm{~min}$ postinjection). Values are means $\pm \mathrm{SE}(n=$ 5-6; ANOVA see text). paws was dose-dependently antagonized by (-)-naloxone, CTOP, and ICI 174,864 but not by nor-BNI (Fig. 5). ANOVA was as follows: PPT by dose of naloxone: $F(3,19)=6.3, p<0.005$, linear regression, $F(1,19)=18.4, p<0.001$; CTOP: $F(2,15)=$ $7.2, p<0.01$, linear regression, $F(1,15)=14.0, p<0.005 ;$ ICI 174,864: $F(2,13)=6.4, p<0.05$, linear regression, $F(1,13)=$ $12.8, p<0.005$; nor-BNI: $F(3,19)=0.3, p>0.05$.

\section{Discussion}

Experiment 1 demonstrates that CWS can produce antinociceptive effects against noxious pressure in both normal and FCA-treated rats. These effects are clearly enhanced in inflamed paws compared to contralateral noninflamed paws or to control animals. The similarity of this phenomenon to that obscrved after systemic administration of exogenous opioid agonists in this model (Stein et al., 1988b) prompted us to put forth the hypothesis that the recruitment of peripheral opioid receptorspecific mechanisms accounts for the augmented antinociceptive effect of CWS in inflamed tissue. We tested this hypothesis by examining whether this effect was reversible by naloxone injected locally into the inflamed paw.

Experiment 2 demonstrates that the antinociceptive effect produced by CWS in inflamed paws can be reversed by locally applied naloxone but not by equivalent doses given systemically. Moreover, this antagonism is stereospecific and dose-dependent. Taken together, these findings are consistent with the notion that CWS can activate local opioid receptor-specific mechanisms in inflamed tissue.

The question arises as to whether antiinflammatory and/or vasoconstrictive effects contribute to this unilateral antinociception. Both of these are unlikely, the former since paw volume did not change during CWS and the latter since temperature decreased to the same extent in both hindpaws and, in contrast to the antinociceptive effect, this drop was not reversible by naloxone. Therefore, we are inclined to invoke a neural mechanism. As discussed extensively in a previous report (Stein et al., 1989a), the most likely location of these peripheral receptors seems to be the primary afferent neuron. This contention is 


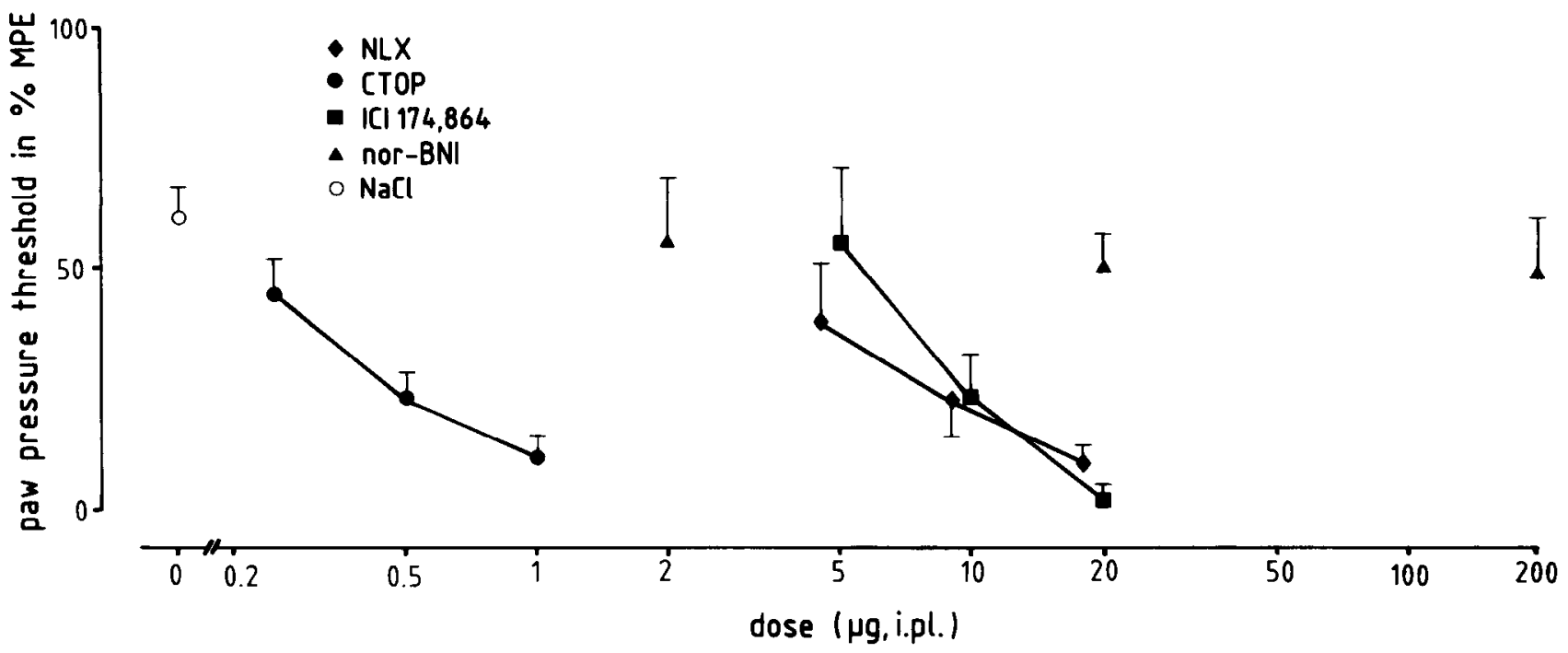

Figure 5. Effects of i.pl. (-)-naloxone (NLX), CTOP, ICI 174,864 , or nor-BNI upon PPT elevation produced by $1 \mu \mathrm{g}$ i.pl. $\beta$-EP in inflamed paws. Values are means $\pm \operatorname{SE}(n=5-6$; ANOVA see text $)$.

supported both by biochemical studies demonstrating opioid binding (LaMotte et al., 1976; Fields et al., 1980; Ninkovic et al., 1982) or opioid modulation of substance $P$ release (Yaksh, 1988) and by electrophysiological data demonstrating opioidspecific effects (Werz and Macdonald, 1982; Frank, 1985; Russell et al., 1987) on sensory neurons. It should be borne in mind, however, that by varying the specific parameters of CWS (e.g., temperature, duration) it may well be possible to activate central opioid and/or nonopioid antinociceptive systems in addition to these peripheral mechanisms.

Previously, we have shown that it is possible to differentiate between the types of peripheral opioid receptors mediating antinociception in this model (Stein et al., 1989a). Therefore, experiment 4 sought to identify the receptor type(s) involved. The results demonstrate that the antinociceptive effect of CWS on inflamed paws can be reversed dose-dependently by antagonists selective for $\mu$ - and $\delta$-, but not for $\kappa$-receptors. Exogenous $\kappa$-agonists, however, can produce peripheral antinociceptive effects in inflammation pointing to the presence of $\kappa$-receptors (Joris et al., 1987; Stein et al., 1988b, 1989a). Thus, it is conceivable that endogenous $\kappa$-ligands may be activated by other environmental stimuli.

Nevertheless, the above findings indicate that opioid agonists with activity at $\mu$ - and/or $\delta$ - but not at $\kappa$-receptors mediate the CWS effect. Inferring from the well-documented binding affin- ities of the endogenous opioid peptides (Höllt, 1986), one would consider cleavage products from either the POMC or the proenkephalin A system, such as $\beta$-EP or the enkephalins, as the most likely candidates. To further delimit the possibilities, we applied antisera against the major representatives of the 3 opioid families in experiment 5 . The results show that both the specific antibody to $\beta$-EP and 3-E7, which exhibits complete immunoreactivity with $\beta$-EP (Gramsch et al., 1983), but not antisera against ME or DYN, can abolish CWS-induced antinociception in inflamed paws.

These findings support the contention that $\mu$ - and $\delta$-receptors in the inflamed paw may be activated by $\beta$-EP released during CWS. This hypothesis, however, is based on the assumption that both $\beta$-EP and opioid receptors display similar binding characteristics in inflamed tissue as in conventional assays (Höllt, 1986). That this may not be correct was already discussed in a previous report (Stein et al., 1989a): First, the anatomical circumstances in peripheral tissue must be considered. Before reaching its presumed locus of action, the peripheral sensory nerve axon or its terminal, an opioid molecule has to traverse several connective tissue and/or lipid membranous barriers. Each peripheral nerve axon is encased in a Schwann cell and, in the case of A $\delta$ fibers, in several layers of lipoid myelin. The nerve fiber lies embedded in the surrounding subcutaneous connective tissue. As in the case of local anesthetics, the milieu $(\mathrm{pH})$ of this

Table 4. Effects of opioid antagonists and antisera on PPT in rats not subjected to CWS

\begin{tabular}{|c|c|c|c|c|c|c|c|c|c|c|c|c|c|c|}
\hline \multirow{2}{*}{$\begin{array}{l}\text { Time } \\
\text { (min) } \\
\end{array}$} & \multicolumn{2}{|c|}{$\underline{\text { CTOP }(1 \mu \mathrm{g})}$} & \multicolumn{2}{|c|}{$\begin{array}{l}\text { ICI } 174,864 \\
(20 \mu \mathrm{g})\end{array}$} & \multicolumn{2}{|c|}{ nor-BNI $(400 \mu \mathrm{g})$} & \multicolumn{2}{|c|}{ 3-E7 $(1 \mu \mathrm{g})$} & \multicolumn{2}{|c|}{$\beta$-EP $(1 \mu \mathrm{g})$} & \multicolumn{2}{|c|}{$\mathrm{ME}(8 \mu \mathrm{g})$} & \multicolumn{2}{|c|}{ DYN $(8 \mu \mathrm{g})$} \\
\hline & $\mathrm{L}$ & $\mathbf{R}$ & $\mathrm{L}$ & $\mathbf{R}$ & $\mathbf{L}$ & $\mathbf{R}$ & $\mathrm{L}$ & $\mathbf{R}$ & $\mathrm{L}$ & $\mathbf{R}$ & $\mathrm{L}$ & $\mathbf{R}$ & $\mathrm{L}$ & $\mathbf{R}$ \\
\hline 0 & $36 \pm 3$ & $29 \pm 6$ & $62 \pm 6$ & 57 & 5 & $50 \pm$ & $47 \pm 3$ & 48 & $32 \pm 2$ & 28 & $45 \pm 9$ & 29 & $43 \pm 5$ & $47 \pm 9$ \\
\hline 5 & $40 \pm 3$ & $35 \pm 3$ & $47 \pm 6$ & $64 \pm 18$ & $56 \pm 10$ & $63 \pm 9$ & $56 \pm 7$ & $42 \pm 4$ & $38 \pm 8$ & $23 \pm 8$ & $36 \pm 4$ & $34 \pm 4$ & $45 \pm 4$ & $60 \pm 11$ \\
\hline 15 & $35 \pm 2$ & $29 \pm 4$ & $53 \pm 6$ & $58 \pm 10$ & $45 \pm 3$ & $55 \pm 15$ & $48 \pm 4$ & $34 \pm 3$ & $29 \pm 2$ & $21 \pm 4$ & $32 \pm 2$ & $22 \pm 2$ & $43 \pm 3$ & $48 \pm 12$ \\
\hline 30 & $34 \pm 2$ & $26 \pm 4$ & $48 \pm 8$ & $53 \pm 9$ & $82 \pm 21$ & $62 \pm 16$ & $48 \pm 5$ & $42 \pm 6$ & $32 \pm 2$ & $23 \pm 6$ & $26 \pm 1$ & $28 \pm 2$ & $44 \pm 3$ & $36 \pm 5$ \\
\hline
\end{tabular}

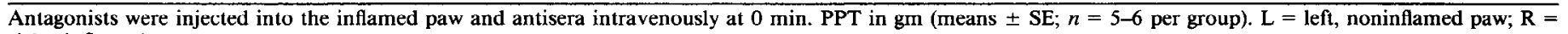
right, inflamed paw. 
environment may crucially influence activity and penetration of the agonist through these layers by altering the relative fraction of agent present in its charged or uncharged forms (Savarese and Covino, 1986). This is of special importance in the acidic conditions of inflamed tissue. Second, changes in tissue $\mathrm{pH}$ may rcsult in altcration of rcceptor conformation which may cntail a transformation from desensitized to active state, or vice versa. Thus, several critical factors have to be considered and one has to be careful in drawing parallels to more customary assays.

For these reasons, we carried out the last experiment investigating the actions of exogenously applied $\beta$-EP. The data clearly demonstrate that intraplantar administration of $\beta$-EP can produce an antinociceptive effect in inflamed paws. This effect is dose-dependent and reversible by naloxone, CTOP, and ICI 174,864 but not by nor-BNI. Moreover, the dose ranges for the antagonists to block the effect of $\beta$-EP are very similar to those required to abolish the effect of CWS on inflamed paws. Apparently, $\beta$-EP displays activity at both $\mu$ - and $\delta$-receptors, which is in line with studies on its central application in vivo (Shook et al., 1988; Bals-Kubik et al., 1990) as well as on in vitro assays (Wüster et al., 1979; Shook et al., 1988).

Taken together, the present evidence strongly indicates that the endogenous ligand that is released during CWS and activates $\mu$ - and $\delta$-receptors in inflamed paws is most likely $\beta$-EP.

One important question remains unanswered: What is the anatomical source for the endogenous opioids released during CWS? The pituitary is the richest source of $\beta$-EP and various stimuli can cause the release of pituitary opioids (Guillemin et al., 1977). Beyond that, however, opioid peptides have been detected in primary sensory neurons (Botticelli et al., 1981; Przewłocki et al., 1983; Weihe et al., 1988). Studies addressing this issue have commenced in our laboratory (Stein et al., 1989b; Parsons et al., 1990).

In summary, we have demonstrated that peripherally located opioid receptors in inflamed tissue can be activated by endogenous opioids released during exposure to environmental stimuli and mediate a decrease of nociception. One of the most likely endogenous ligands appears to be $\beta$-EP.

\section{References}

Bals-Kubik, R., T. S. Shippenberg, and A. Herz (1990) Involvement of central $\mu$ and $\delta$ opioid receptors in mediating the reinforcing effects of $\beta$-endorphin in the rat. Eur. J. Pharmacol. 175: 63-69.

Bodnar, R. J. (1986) Neuropharmacological and neuroendocrine substrates of stress-induced analgesia. Ann. NY Acad. Sci. 467: 345360.

Botticelli, L. J., B. M. Cox, and A. Goldstein (1981) Immunoreactive dynorphin in mammalian spinal cord and dorsal root ganglia. Proc. Natl. Acad. Sci. USA 78: 7783-7786.

Cotton, R., M. G. Giles, L. Miller, J. S. Shaw, and D. Timms (1984) ICI 174,864: A highly selective antagonist for the opioid $\delta$-receptor. Eur. J. Pharmacol. 97: 331-332.

Ferreira, S. H., and M. Nakamura (1979) Prostaglandin hyperalgesia: The peripheral analgesic activity of morphine, enkephalins and opioid antagonists. Prostaglandins 18: 191-200.

Fields, H. L., P. C. Emson, B. K. Leigh, R. F. T. Gilbert, and L. L. Iversen (1980) Multiple opiate receptor sites on primary afferent fibres. Nature 284: 351-353.

Frank, G. B. (1985) Stereospecific opioid receptors on excitable cell membranes. Can. J. Physiol. Pharmacol. 63: 1023-1032.

Gramsch, C., T. Meo, G. Riethmüller, and A. Herz (1983) Binding characteristics of a monoclonal $\beta$-endorphin antibody recognizing the N-terminus of opioid peptides. J. Neurochem. 40: 1220-1226.

Guillemin, R., T. Vargo, J. Rossier, S. Minick, N. Ling, C. Rivier, W. Vale, and F. Bloom (1977) $\beta$-endorphin and adrenocorticotropin are secreted concomitantly by the pituitary gland. Science 197: 13671369.
Gulya, K., J. T. Pelton, V. J. Hruby, and H. I. Yamamura (1986) Cyclic somatostatin octapeptide analogues with high affinity and selectivity toward mu opioid receptors. Life Sci. 38: 2221-2229.

Höllt, V. (1986) Opioid peptide processing and receptor selectivity. Annu. Rev. Pharmacol. Toxicol. 26: 59-77.

Joris, J. L., R. Dubner, and K. M. Hargreaves (1987) Opioid analgesia at peripheral sites: A target for opioids released during stress and inflammation. Anesth. Analg. 66: 1277-1281.

Kirk, E. R. (1982) Experimental Design: Procedures for the Behavioral Sciences, Brooks/Cole, Monterey, CA.

LaMotte, C., C. B. Pert, and S. H. Synder (1976) Opiate receptor binding in primate spinal cord: Distribution and changes after dorsal root section. Brain Res. 112: 407-412.

Lewis, J., A. Mansour, H. Khachaturian, S. J. Watson, and H. Akil (1987) Opioids and pain regulation. In: Opioid Systems and Analgesia, J. W. Lewis and H. Akil, eds., pp. 129-159, Karger, Basel.

Millan, M. J., and A. Herz (1985) The endocrinology of the opioids. Int. Rev. Neurobiol. 26: 1-83.

Ninkovic, M., S. P. Hunt, and J. R. W. Gleave (1982) Localization of opiate and histamine $\mathrm{H}_{1}$-receptors in the primary sensory ganglia and spinal cord. Brain Res. 241: 197-206.

Parsons, C. G., A. Czlonkowski, C. Stein, and A. Herz (1990) Peripheral opioid receptors mediating antinociception in inflammation. Activation by endogenous opioids and role of the pituitary-adrenal axis. Pain (in press).

Portoghese, P. S., A. W. Lipkowski, and A. E. Takemori (1987) Binaltorphimine and nor-binaltorphimine, potent and selective $\kappa$-opioid receptor antagonists. Life Sci. 40: 1287-1292.

Przewłocki, R., C. Gramsch, A. Pasi, and A. Herz (1983) Characterization and localization of immunoreactive dynorphin, $\alpha$-neoendorphin, met-enkephalin and substance $\mathbf{P}$ in human spinal cord. Brain Res. 280: 95-103

Russell, N. J. W., H.-G. Schaible, and R. F. Schmidt (1987) Opiates inhibit the discharges of fine afferent units from inflamed knee joint of the cat. Neurosci. Lett. 76: 107-112.

Savarese, J. J., and B. G. Covino (1986) Basic and clinical pharmacology of local anesthetic drugs. In Anesthesia, 2nd ed., R. D. Miller, ed., pp. 985-1013, Churchill Livingstone, New York.

Shook, J. E., W. Kazmierski, W. S. Wire, P. K. Lemcke, V. J. Hruby, and T. F. Burks (1988) Opioid receptor selectivity of $\beta$-endorphin in vitro and in vivo: $\mathrm{Mu}$, delta and epsilon receptors. J. Pharmacol. Exp. Ther. 246: 1018-1025.

Stein, C., M. J. Millan, and A. Herz (1988a) Unilateral inflammation of the hindpaw in rats as a model of prolonged noxious stimulation: Alterations in behavior and nociceptive thresholds. Pharmacol. Biochem. Behav. 31: 445-451.

Stein, C., M. J. Millan, A. Yassouridis, and A. Herz (1988b) Antinociceptive effects of $\mu$ - and $\kappa$-agonists in inflammation are enhanced by a peripheral opioid receptor-specific mechanism. Eur. J. Pharmacol. 155: 255-264.

Stein, C., M. J. Millan, T. S. Shippenberg, K. Peter, and A. Herz (1989a) Peripheral opioid receptors mediating antinociception in inflammation. Evidence for involvement of $\mathrm{mu}$, delta and kappa receptors. J. Pharmacol. Exp. Ther. 248: 1269-1275.

Stein, C., C. G. Parsons, and A. Herz (1989b) Stress-induced analgesia in a model of inflammation: Mediation by peripheral opioid receptors and involvement of pituitary. Naunyn-Schmiedeberg's Arch. Pharmacol. 339: R 101.

Terman, G. W., Y. Shavit, J. W. Lewis, T. J. Cannon, and J. C. Liebeskind (1984) Intrinsic mechanisms of pain inhibition: Activation by stress. Science $226: 1270-1277$.

Weihe, E., D. Nohr, and W. Hartschuh (1988) Immunohistochemical evidence for a co-transmitter role of opioid peptides in primary sensory neurons. Prog. Brain Res. 74: 189-199.

Werz, M. A., and R. L. Macdonald (1982) Heterogeneous sensitivity of cultured dorsal root ganglion neurones to opioid peptides selective for $\mu$ - and $\delta$-opiate receptors. Nature 299: 730-733.

Wüster, M., R. Schulz, and A. Herz (1979) Specificity of opioids towards the $\mu-, \delta$ - and $\epsilon$-opiate receptors. Neurosci. Lett. 15: 193-198.

Yaksh, T. L. (1988) Substance P release from knee joint afferent terminals: Modulation by opioids. Brain Res. 458: 319-324.

Zimmermann, M. (1983) Ethical guidelines for investigations of experimental pain in conscious animals (Guest Editorial). Pain 16: 109_ 110. 